\title{
Synthesis and Characterization of Low-Cost Activated Carbons for Pollutants Removal from Automotive Emissions
}

\author{
Pedro Julio Villegas* \\ CUBEL Consultancy, Central America
}

Submission: May 10, 2018; Published: May 21, 2018

"Corresponding author: Pedro Julio Villegas, CUBEL Consultancy, \#375 Baron Bliss Street, Benque Viejo Town, Cayo District, Belize, Central America, Tel: +501 631 8812; Email: cubel.consultancy@hotmail.com; pjva00@hotmail.com

Abstract

Air purification is one of the most widely known environmental applications of activated carbons. In order to guarantee the successful removal of contaminants and pollutants on activated carbons, the development of new adsorbents has been increasing in the last few years. This paper presents a systematic study for cleaning vehicles emissions of $\mathrm{CO}, \mathrm{SO}_{2}, \mathrm{NO}_{2}$ and $\mathrm{H}_{2} \mathrm{~S}$ using the process of physical adsorption on novel adsorbents obtained from tropical biomasses. Use of this simple method is a valuable alternative to meet emission standards in Developing Countries. It is known that the agricultural wastes studied here are a feasible alternative for granular activated carbons preparation for pollutants removal during engines operation, approaching its efficiency to the commercial Catalytic Converters.

Keywords: Combustion gases purification; Activated carbons; Adsorption and adsorbents; Pollutants removal

\section{Introduction}

Wastes cannot be introduced to the environment in unlimited amounts, especially in case of air pollutants. Different measures have been taken to limit the pollution emission. These are e.g.: the elimination of technological processes generating a lot of waste, introduction of new technologies which minimize the contamination, etc. If it is not possible to reduce the emissions, the waste gas must be purified [1,2]. Nowadays, the economic conditions of Developing Countries don't allow that all individuals own a new automotive. It is necessary to develop alternatives to reduce the negative environmental impact associated with obsolete engines operation. The best way to address it is by reducing certain exhaust gas components during fuel combustion. The answer therefore is to look at vehicles as an integral whole to identify which solutions would be more feasible. Taking this holistic approach to vehicle improvement as a basis, three main exhaust emission control strategies can be defined:
a. Reduction of fuel consumption;
b. Exhaust gas treatment, and
c. Performance monitoring.

From these three alternatives the second one is currently the more effective for air quality improvement. The main gas treatment currently used is the Catalytic Converter, typically comprises of an expensive porous ceramic substrate with large surface area [3]. Unfortunately some users in Central America and the Caribbe an Countries tend to remove the Catalytic Converter from the vehicles to get better power loads. Over the last decade, the study of combustion gas treatment has been focused on more sophisticated Catalytic Converters. Consequently, the study of other alternatives for exhaust gas purification is important. There are a few methods to purify harmful combustion gases such as physical adsorption $[4,5]$, chemical absorption [6], catalytic methods, etc. [7,8]. It is necessary then to select a suitable method to purify harmful gas for Developing Countries. Besides, standards for vehicles become more mandatory day to day. The more feasible alternative would be the development of customized activated carbons filters for the betterment of the environment. This can be accomplished by reducing the emissions that contribute to smog and acid rains [9].

Activated carbons can be obtained from different precursors, with benefits to the environment [10-12]. Due to its chemical composition, forest biomasses are valuable sources in the synthesis of adsorbents materials. Several examples of activated carbons preparation can be found in the open literature $[13,14]$. They have been used among others in the purification of pollutants gases such as carbon dioxide, sulfur dioxide, hydrogen sulfide, nitrogen oxides and mercury [15-17]. Taking into account this background, the main objectives of this work can be summarized as follows:

I. Study the feasibility of some agricultural wastes as raw material for activated carbons production with high specific surface area, high mechanical resistance and wide availability. 
II. Definition of the best experimental conditions for "chemical activation" with H3PO4 such as "physical activation" with steam water for each precursor.

III. Study of the elimination of pollutant gases in vehicles engines with filters of the adsorbents produced.

IV. Proposal of a methodology for filters evaluation in the removal of undesirable pollutants $\left(\mathrm{CO}, \mathrm{SO}_{2}, \mathrm{NO}_{2}\right.$ and $\left.\mathrm{H}_{2} \mathrm{~S}\right)$ during engines operation.

The practical aspects addressed in this research cover the broad spectrum of applications for air cleaning. Better engines performances can be obtained with an adsorption technique of activated carbons, through an extremely economic method.

\section{Materials and Methods}

The raw materials selected for the study are presented in Tables 1-3.

Table 1: Precursors studied.

\begin{tabular}{|c|c|}
\hline Common Name & Scientific Name \\
\hline Tropical Bamboo & Bambusoideae Bambuseae \\
\hline Central American Mahogany & Khaya Spp \\
\hline Honduran Mahogany & Swietenia Macrophylla \\
\hline Mamey Zapote & Pouteria Sapota \\
\hline Corncobs & Zea Mays \\
\hline
\end{tabular}

Table 2.

\begin{tabular}{|c|c|}
\hline For the Physical Activation & For the Chemical Activation \\
\hline $\mathrm{T}=600-800^{\circ} \mathrm{C} ;$ & $\mathrm{T}=300-500{ }^{\circ} \mathrm{C} ;$ \\
\hline $\mathrm{t}=60-120 \mathrm{~min}$. & $\mathrm{t}=30-120 \mathrm{~min} . ;$ \\
\hline Activating agent: $\mathrm{H}_{2} \mathrm{O} ;$ & Heating speed: $5{ }^{\circ} \mathrm{C} / \mathrm{min}$. \\
\hline Heating speed: $10{ }^{\circ} \mathrm{C} / \mathrm{min}$. & $\mathrm{C}\left(\mathrm{H}_{3} \mathrm{PO}_{4}\right)=50 \% \mathrm{w} / \mathrm{w}$. \\
\hline
\end{tabular}

Table 3.

\begin{tabular}{|c|c|c|c|c|c|c|c|}
\hline \multicolumn{3}{|c|}{ For the Physical Activation } & \multicolumn{3}{c|}{ For the Chemical Activation } \\
\hline Variable & -1 & 0 & +1 & Variable & -1 & 0 & +1 \\
\hline $\mathrm{T}\left({ }^{\circ} \mathrm{C}\right)$ & 600 & 700 & 800 & $\mathrm{~T}\left({ }^{\circ} \mathrm{C}\right)$ & 300 & 400 & 500 \\
\hline $\mathrm{t}($ min.) & 60 & 90 & 120 & $\mathrm{t}(\mathrm{min})$. & 60 & 90 & 120 \\
\hline & & & $\begin{array}{c}\mathrm{C} \\
\left(\mathrm{H}_{3} \mathrm{PO}_{4}\right) \\
(\%)\end{array}$ & \multicolumn{4}{|c|}{50} \\
\hline
\end{tabular}

\section{Preparation of Activated Carbons}

The starting raw materials were cut up in small pieces and next subjected to pyrolysis. This process was carried out in a tubular reactor in nitrogen atmosphere. The samples were heated $\left(10^{\circ} \mathrm{C} /\right.$ $\mathrm{min}$ ) from room temperature to the final pyrolysis temperature of 500. In the final pyrolysis temperature, samples were kept for 60 minutes and then cooled down. The solid products of pyrolysis were next subjected to physical activation [18]. In the case of chemical activation the raw materials were the original precursors which were overnight impregnated into $\mathrm{H}_{3} \mathrm{PO}_{4}$ and later submitted to pyrolysis into a stainless steel reactor of $30 \mathrm{~cm}$ of length per $3 \mathrm{~cm}$ of diameter. Once the reactor reached the desired temperature the samples were kept at the final temperature according to the experimental conditions of the specific experiment. The activated products then cooled down and washed with enough water till get a neutral $\mathrm{pH}$. Finally, the products were dry at $120^{\circ} \mathrm{C}$ and then stored [19]. Two different processes were used for the synthesis of the activated carbons from the chars previously obtained by pyrolysis. [18,19]. The experimental conditions used were:

Factorial experimental designs $3^{2}$ were executed to evaluate the simultaneous influence of the activation conditions on the final product features $[14,20]$. Following the details for both synthesis processes:

Key properties of the activated carbons prepared were analyzed:

a. Raw material availability;

b. High specific surface area;

c. High mechanical resistance;

d. High adsorption speed.

\section{Characterization of the Raw Materials and Synthetized Activated Carbons}

Elemental Analysis: The amount of elements (carbon, hydrogen, nitrogen and oxygen) in the raw materials was determined by an Elemental Analyzer by flash combustion. The samples were firstly dried in an oven at $110^{\circ} \mathrm{C}$ before the measurement was carried out. The materials was burned at a temperature of $1000^{\circ} \mathrm{C}$ in flowing oxygen for $\mathrm{C}, \mathrm{H}$ and $\mathrm{N}$ analysis in the analyzer. The $\mathrm{CO}_{2}, \mathrm{H}_{2} \mathrm{O}$ and NOx combustion gases were passed through a reduction tube with helium as the carrier gas to convert the NOx nitrogen oxides into $\mathrm{N}_{2}$ and bind the free oxygen. The $\mathrm{CO}_{2}$ and $\mathrm{H}_{2} \mathrm{O}$ were measured by selective IR detector. After corresponding absorption of these gases, the content of the remaining nitrogen was determined by thermal conductivity detection. The oxygen was calculated by the difference of carbon, hydrogen and nitrogen.

Apparent Density Measurement: Apparent Density is a measure of the mass per unit volume of a material. It is also called Bulk Density and provides a measure of the "fluffiness" of a material in its natural form. In this work the Standard ASTM D1895 was used. According to this standard the materials are poured into a cylinder of known volume (e.g. $100 \mathrm{~mL}$ pipettes) and later weight. Apparent density was calculated as the mass of material divided by the volume occupied into the cylinder [21].

Specific Surface Area Measurement: In order to examine the structure of the synthetized materials, the measurement of the specific surface area of the activated carbons was carried out by gas adsorption isotherms using a Sorptometer applying BET Model. All samples were degassed at $200^{\circ} \mathrm{C}$ prior to $\mathrm{N}_{2}$ adsorption measurements. Specific surface area was determined by a multipoint BET method using the adsorption data in the relative pressure range: 0.05-0.3 [22,23]. 
Mechanical Resistance Measurement: The mechanical resistance of the obtained activated carbons was measured through a simple method. A know mass of the granular material was impacted by six glass balls into a semispherical container of stainless steel. The percentage relation between the fragmented mass retained in a $0.5 \mathrm{~mm}$ mesh and the initial mass is used to estimate the mechanical resistance [24].

Adsorption Speed Evaluation: The adsorption speed was determined by Arrhenius Equation:

$$
\frac{\mathbb{X}}{\boldsymbol{t}}=k_{a d s}^{\prime} * \alpha
$$

where: $\mathbf{x} / \mathbf{d}$ is speed of the adsorption process studied; $\alpha$ is the residual concentration of the adsorbed; and $\mathbf{k}_{\text {ads }}^{\prime}$ the apparent kinetic constant of the adsorption process that can be determined by:

$$
\mathbf{k}_{\text {ads }}^{\prime}=\mathbf{k}_{0} \exp \left\{-\frac{\mathbf{K}}{\mathbf{R}}\right\}
$$

(Equation 2)

Applying logarithm to (Equation 2) brings the possibility to change an exponential equation into a linear dependence, see below:

$$
\mathbf{h} \mathbf{k}_{\text {ads }}^{\prime}=\mathbf{h ~ k _ { 0 }}-\frac{\mathbf{K}}{\mathbf{R}} * \frac{\mathbf{1}}{\mathbf{T}}
$$

Plotting $\mathbf{h} \mathbf{k}_{\text {ads }}^{\prime}$ vs $\mathbf{1} / \mathbf{T}$ the activation energy (EA) and the preexponential factor $(\mathrm{k} 0)$ of the adsorption process studied can be calculated. In the Results discussion $\mathbf{k}^{\prime}{ }_{\text {ads }}$ will be refers as $\mathrm{K}$ for practical reasons.

\section{Designing Process of Activated Carbon Filters}

Figure 1 illustrates the process of activated carbon units customized assembling. These filters are very useful to study pollutant gases elimination in automotive engines with the adsorbents produced [25]. The samples, in the form of granules of 2-5 mm in diameter, were packed into a steel column (length 300 $\mathrm{mm}$ and internal diameter $90 \mathrm{~mm}$ ). The gas was passed through the bed of the adsorbent at $0.50 \mathrm{~L} / \mathrm{min}$. The concentration of $\mathrm{CO}$, $\mathrm{SO}_{2}, \mathrm{NO}_{2}$ and $\mathrm{H}_{2} \mathrm{~S}$ were monitored using a Gas Chromatograph Equipment with standard TCD detector. The concentrations were calculated by integration of the area above the curves.

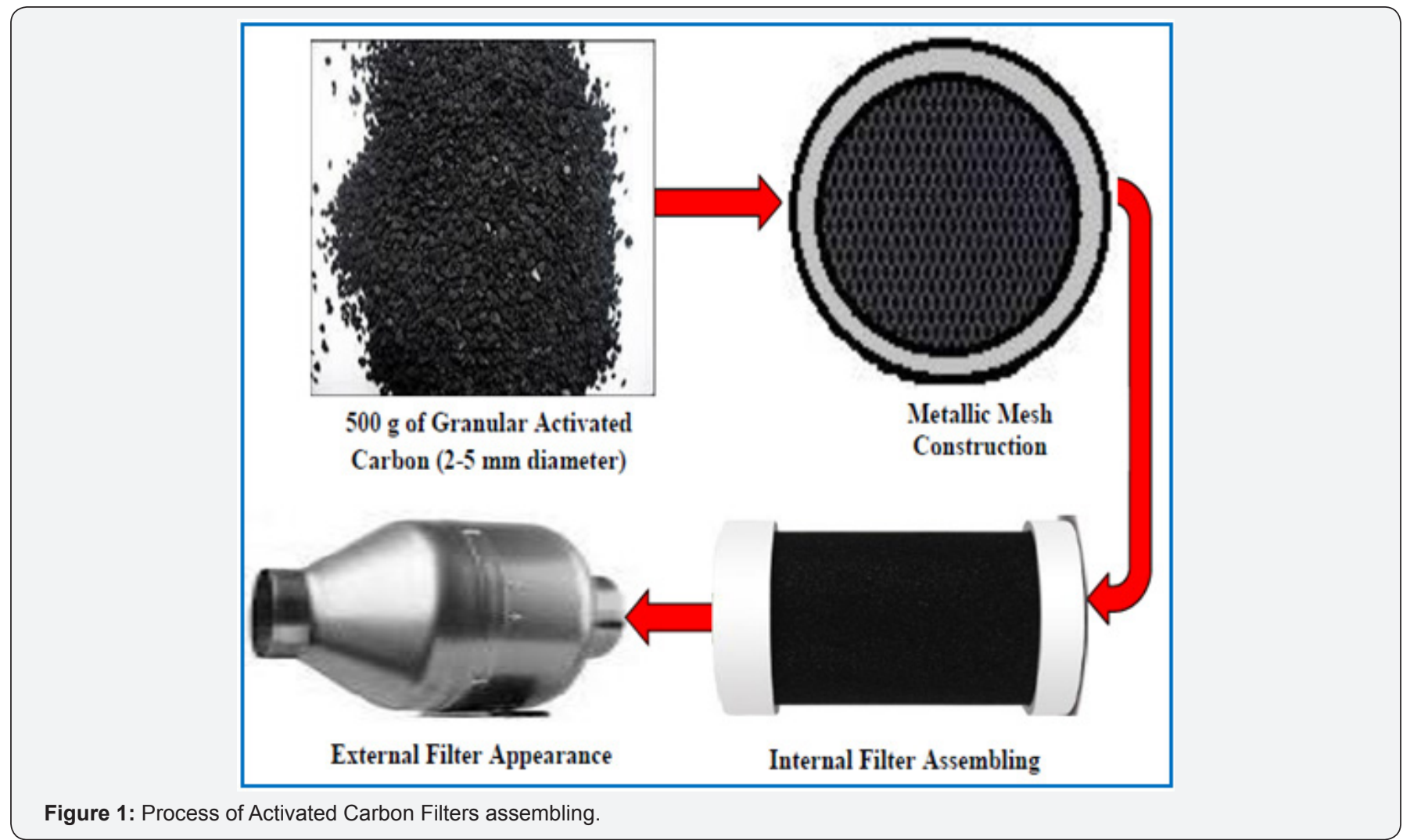

\section{Pollutants Monitoring at Laboratory Scale}

There is no known method available in the open literature which is capable of simultaneously determining all components of combustion gas evaluated here [2]. So the method developed in this work in an innovative alternative for Developing Countries. In order to determine the suitability of the obtained adsorbents in the elimination of $\mathrm{CO}, \mathrm{SO}_{2}, \mathrm{NO}_{2}$ and $\mathrm{H}_{2} \mathrm{~S}$, the pollutants removal rate was determined. Figure 2 show a schematic diagram of the customized laboratory system for pollutants monitoring. The system includes, among others:

a. 6 cylinder automotive engine;

b. $\quad$ Activated carbon filter;

c. Exhaust gas analyzer device (Gas Chromatograph);

d. Computer system for data acquisition and recording, etc. 


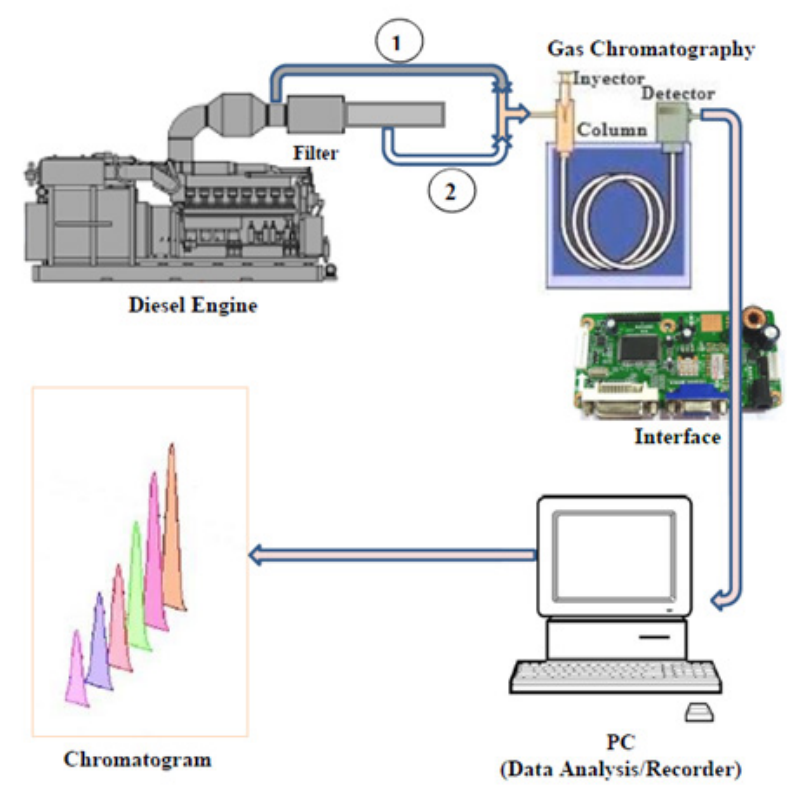

Figure 2: Pollutants Monitoring System (1, 2: Gas sampling before and after pollutants removal).

Gas Monitoring System: A standard gas chromatography was used with the following specs:

i. Detector: TCD;

ii. Carrier: Helium;

iii. Column: Porapak Q and Molecular Sieve 5A;

iv. Oven Temperature: $100^{\circ} \mathrm{C}$;

v. Sample volume: $1 \mathrm{ml}$;

vi. $\quad$ Carrier Flow: $25 \mathrm{ml} / \mathrm{min}$;

vii. Detector Temperature: $120^{\circ} \mathrm{C}$

Under the described chromatographic conditions, the four gases could be easily separated and quantified $[25,26]$.

The methodology used starting with the preparation of the calibration gas sample by injecting known volumes of each of the four pure gases $\left(\mathrm{CO}, \mathrm{SO}_{2}, \mathrm{NO}_{2}\right.$ and $\mathrm{H}_{2} \mathrm{~S}$ ) and balance nitrogen into adequate Gas Sampling Bag through the bag's rubber septum. One $\mathrm{mL}$ of the calibration gas mixture and the combustion gases were analyzed by a GC system. Randomly measures of combustion gases before and after the purification process were made on a similar manner in order to evaluate the removal rate of the undesirable pollutants.

\section{Results and Discussion}

\section{Composition and Physical Properties of Raw Materials and Synthetized Products}

Table 4 brings a summary of the chemical composition (elemental analysis), such as some physical properties of the 5 precursors studied. Elemental nitrogen, carbon and hydrogen were determined from the elemental analyzer by flash combustion while oxygen was determined by the difference of these three elements. Table 4 shows that the largest amount of element in the raw materials was carbon (except for Corncob which had smaller amount of carbon than oxygen), followed by oxygen, and the smallest amount was nitrogen. The lower content of carbon for Corncob can be attributed to a higher content of volatiles in the structure, translated into a high porosity for the raw material. All precursors do not contain sulfur in their structure, which is very favorable from the ecological and technological points of view.

Table 4: Chemical composition and some physical properties of the raw materials studied.

\begin{tabular}{|c|c|c|c|c|c|c|c|c|}
\hline \multirow{2}{*}{ Raw Material } & \multicolumn{4}{|c|}{ Chemical Composition } & \multicolumn{4}{c|}{ Physical Properties } \\
\cline { 2 - 10 } & $\mathbf{\% C}$ & $\mathbf{\% H}$ & $\mathbf{\% O}$ & $\mathbf{\% N}$ & $\mathbf{0 / C}$ & $\mathbf{d}_{\mathbf{a p}} \mathbf{( g / \mathbf { c m } ^ { 3 } )}$ & $\mathbf{d}_{\mathbf{r}}\left(\mathbf{g} / \mathbf{c m}^{3}\right)$ & $\mathbf{P}(\mathbf{\%})$ \\
\hline Tropical Bamboo & 47.3 & 8.4 & 43.9 & 0.4 & 0.93 & 0.350 & 0.604 & 0.35 \\
\hline Mamey Zapote & 58.5 & 5.5 & 35.1 & 0.9 & 0.60 & 0.750 & 1.080 & 0.35 \\
\hline Central American Mahogany & 53.9 & 5.1 & 40.0 & 1.0 & 0.74 & 0.382 & 0.612 & 0.37 \\
\hline Honduran Mahogany & 54.2 & 5.1 & 39.7 & 1.0 & 0.73 & 0.371 & 0.750 & 0.50 \\
\hline Common Corncobs & 42.9 & 4.9 & 51.5 & 0.7 & 1.20 & 0.168 & 0.420 & 0.79 \\
\hline
\end{tabular}

$\mathbf{d}_{\mathrm{ap}}$ : apparent density; $\mathbf{d}_{\mathbf{r}}$ : real density; $\mathbf{P}$ : porosity. 
The activation process increases carbon amount $(\sim 20-$ $40 \%$ ) after modification. On the contrary, there was a reduction in the oxygen content $(\sim 20-30 \%)$ after physical and chemical modifications. There will be also a reduction of hydrogen amount. The amount of nitrogen was so small for all materials. In Table 4

Table 5: Best materials from physical activation with steam water. it can be observed that the initial porosity of all material, except corncobs, have lower values, below 0.5 , it makes these materials adequate for activated carbons preparation through chemical or physical activation. The best products synthetized by each process will be reported in Tables $5 \& 6$.

\begin{tabular}{|c|c|c|c|c|c|c|c|}
\hline Activated Carbon From & $\mathbf{T}\left({ }^{\circ} \mathbf{C}\right)$ & $\mathbf{t}(\mathbf{m i n})$ & $\mathbf{S}\left(\mathbf{m}^{2} \mathbf{g}\right)$ & $\mathbf{K}\left(\mathbf{m i n}^{-1}\right)$ & $\mathbf{Y}(\mathbf{\%})$ & $\mathbf{M}_{\mathbf{r}} \mathbf{( \% )}$ & $\mathbf{d}_{\mathbf{a p}}\left(\mathbf{g} / \mathbf{c m}^{3}\right)$ \\
\hline Tropical Bamboo & 800 & 60 & 875 & 0.135 & 23.2 & 84.4 & 0.294 \\
\hline Mamey Zapote & 800 & 60 & 940 & 0.147 & 39.1 & 91.7 & 0.329 \\
\hline Central American Mahogany & 700 & 90 & 847 & 0.200 & 38.6 & 85.0 & 0.257 \\
\hline Honduran Mahogany & 800 & 60 & 889 & 0.196 & 37.1 & 86.9 & 0.292 \\
\hline Common Corncobs & 700 & 60 & 507 & 0.159 & 17.4 & 71.7 & 0.080 \\
\hline
\end{tabular}

S: specific surface; $\mathbf{K}$ : apparent kinetic constant of the adsorption process; $\mathbf{Y}:$ yield; $\mathbf{M}_{\mathbf{r}}$ : mechanical resistance; $\mathbf{d}_{\mathrm{ap}}$ : apparent density.

Table 6: Best materials from Chemical activation with $50 \%$ of $\mathrm{H}_{3} \mathrm{PO}_{4}$.

\begin{tabular}{|c|c|c|c|c|c|c|c|}
\hline Activated Carbon From & $\mathbf{T}\left({ }^{\circ} \mathbf{C}\right)$ & $\mathbf{t}(\mathbf{m i n})$ & $\mathbf{S}\left(\mathbf{m}^{2} \mathbf{g}\right)$ & $\mathbf{K}\left(\mathbf{m i n}^{-1}\right)$ & $\mathbf{Y}(\%)$ & $\mathbf{M}_{\mathbf{r}}(\mathbf{\%})$ & $\mathbf{d}_{\mathbf{a p}}\left(\mathbf{g} / \mathbf{c m}^{\mathbf{3}}\right)$ \\
\hline Tropical Bamboo & 500 & 120 & 700 & 0.110 & 30.5 & 85.6 & 0.284 \\
\hline Mamey Zapote & 500 & 90 & 805 & 0.203 & 34.7 & 90.9 & 0.317 \\
\hline Central American Mahogany & 500 & 90 & 832 & 0.270 & 34.9 & 90.1 & 0.295 \\
\hline Honduran Mahogany & 500 & 90 & 706 & 0.126 & 33.3 & 88.9 & 0.272 \\
\hline Common Corncobs & 500 & 60 & 470 & 0.142 & 20.3 & 72.3 & 0.120 \\
\hline
\end{tabular}

S: specific surface; $\mathbf{K}$ : apparent kinetic constant of the adsorption process; $\mathbf{Y}$ : yield; $\mathbf{M}_{\mathbf{r}}$ : mechanical resistance; $\mathbf{d}_{\mathrm{ap}}$ : apparent density.

Activated carbon from Central American Mahogany was the more reactive material with a significant porosity development $\left(\mathrm{S}=847 \mathrm{~m}^{2} / \mathrm{g}\right.$ ). Should be noted also that Activated carbon from Mamey Zapote was the best adsorbent $\left(\mathrm{S}=940 \mathrm{~m}^{2} / \mathrm{g}\right)$ and also have the higher mechanical resistance, yield and apparent density, very important for filters durability, but it's the less available material. Finally it's necessary to remark that Common Corncobs, a widely available agricultural by-product in Central American Countries, showed the worst results for all adsorbents properties; it can be attributable to the higher porosity of the initial raw material $(\mathrm{P}=$ $0.79 \%)$.

Table 6 show that activated carbon from Central American Mahogany was again the more reactive material but registered now the higher yield and adsorbent area ( $\mathrm{S}=832 \mathrm{~m}^{2} / \mathrm{g}$ ). Furthermore, Activated carbon from Mamey Zapote was the second better adsorbent $\left(\mathrm{S}=805 \mathrm{~m}^{2} / \mathrm{g}\right.$ ) and again have the higher mechanical resistance and apparent density. One more time activated carbon from Common Corncobs was the worst adsorbent $\left(\mathrm{S}=470 \mathrm{~m}^{2} / \mathrm{g}\right.$ ). This fact is a consequence of poorly porous structure development during the activation process. Further analysis of the data from Tables $5 \& 6$ indicates that irrespectively of the variant used, the process of activation leads to further changes in the structure of carbonaceous material. The activated carbons synthetized from different materials studied here differ significantly mainly in the specific surface area development. The adsorbents differ not only in the surface properties but also in their texture and morphology that depend first of all on the variant of activation and the pyrolysis conditions of the initial material. Figure 3 illustrates the differences in specific surface development with both methods and the same materials.

In Figure 3, it can clearly be observed that larger specific surface area developments were achieved with physical activation processes. Those products were the better adsorbents to remove the undesirable pollutants. It also confirms that the factorial experimental designs used are the most suitable to optimize the conditions for activated carbon preparation. Textural parameters significantly affect the adsorption properties of the samples studied. ${ }^{[5]}$ This observation suggests that the functional groups of the surface also have considerable influence on the abilities for combustion gases removal. All adsorbents studied had a rapid decrease in $\mathrm{CO}, \mathrm{SO}_{2}, \mathrm{NO}_{2}$ and $\mathrm{H}_{2} \mathrm{~S}$ concentration after gases interacted with the corresponding filters. High intensity of these harmful gas reductions at ambient conditions can be the reason for much better adsorption on higher surface area products. This explains the lower efficiency of gases removal by chemically activated carbons. The chemical activation process has the additional disadvantage of the required product washing after preparation which inevitably aggregates additional costs. 


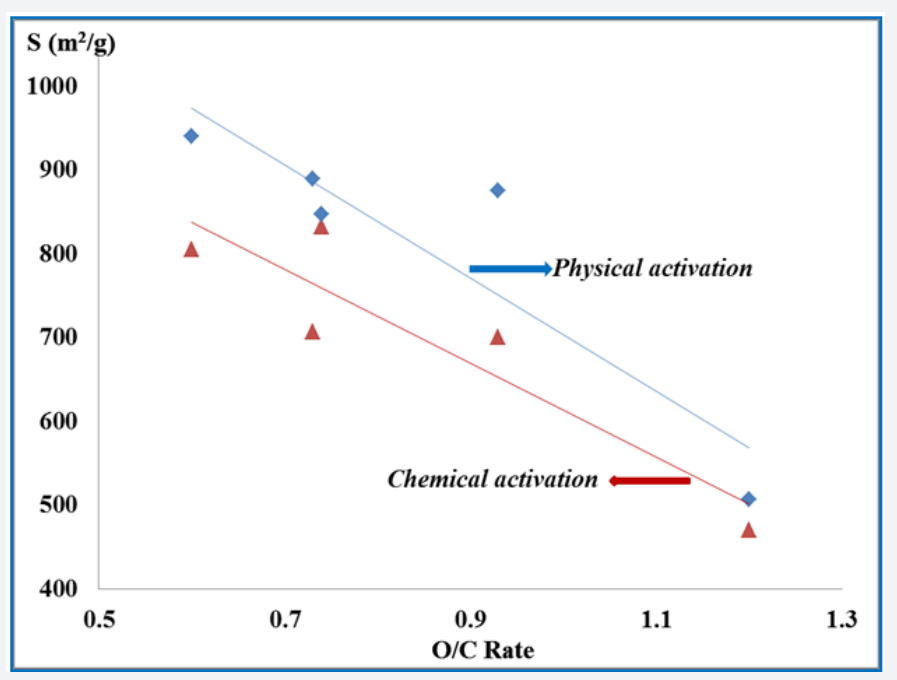

Figure 3: Specific surface development using different activation methods and same materials.

\section{Gas Monitoring System}

The calibrating gas analysis through the regression equations obtained from triplicate analysis of the gas mixtures at identical concentrations, revealed excellent agreement with the known concentrations. The pollutants monitoring system and analytical method used were effective for the simultaneous analyses of the four toxic combustion gases. Figure 4 shows two examples of 2 chromatograms obtained during the analysis of combustion gases purified with activated carbons from Mamey Zapote physically activated. In this figure it can clearly be observed the significant difference before and after gases interaction with adsorbents that can remove large amount of these undesirable gases with the associated environmental benefits.

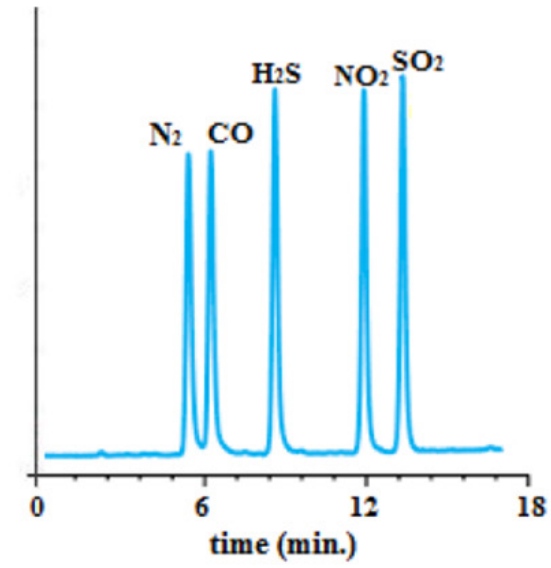

(a) Before purification with Activated Carbon

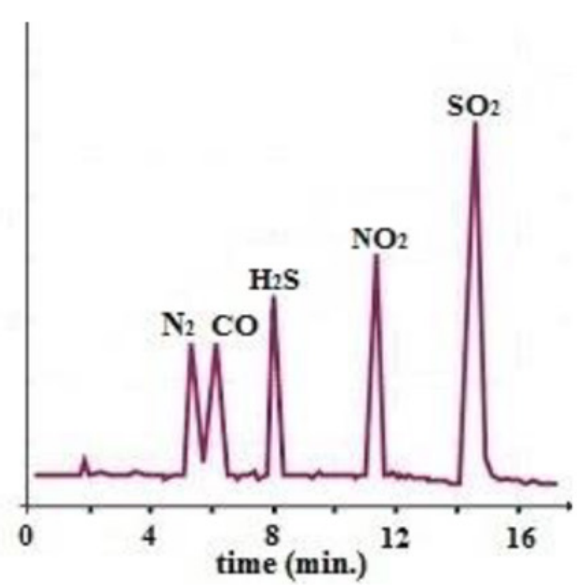

(b) After interaction with Mamey Zapote physically activated

Figure 4: Chromatographic analysis of automotive engine combustion gases.

The analyses of combustion gases revealed moderate concentrations of $\mathrm{H}_{2} \mathrm{~S}$ and $\mathrm{CO}$ but very high concentrations of $\mathrm{SO}_{2}$ and $\mathrm{NO}_{2}$. The most effective adsorbent to remove these gases were the physically activated ones. At the present state of knowledge we can only speculate about the reasons for such poor results obtained from the chemically activated samples. Most probably the reason is the presence of a large number of acidic groups on their surface, in contrast to the physically activated samples, that probably have more basic functional groups present on the surface of the samples. Other chemicals present in the combustion atmospheres did not appear to interfere with the analyses. The chromatographic peaks were well separated and defined and the gases were present in amounts that could be easily determined. An excellent precision with relative standard deviations significantly below $2 \%$ were achieved in all gas monitoring analysis. The speed, sensitivity and selectivity of the used method make it suitable for analyzing combustion gas mixture of the four gases studied. Table 7 shows the overall average values of pollutants removal with activated carbons (A.C.) during automotive engines combustion.

In Table 7 it can clearly be observed that $\mathrm{SO}_{2}$ and $\mathrm{NO}_{2}$ amounts monitored are remarkable higher than the average limit values for $24 \mathrm{~h}$. The good news is that the activated carbons studied can 


\section{Organic and Medicinal Chemistry International Journal}

efficiently remove about $80 \%$ of pollutants in exhaust gases from automotive engines with the added value that the harmful gases concentration goes below the limit values. Figure 5 show the correlation between pollutants removal rate and specific surface area of activated carbons during automotive engines operation.
In Figure 5 it can be clearly be observed that higher activated carbons specific surface area translated into higher pollutants removal rates that could be estimated by the equation 4 with a correlation coefficient $R_{2}=0.995$ :

$$
\text { R moval Rate }=\frac{S-5.3}{9.9}
$$

(Equation 4)

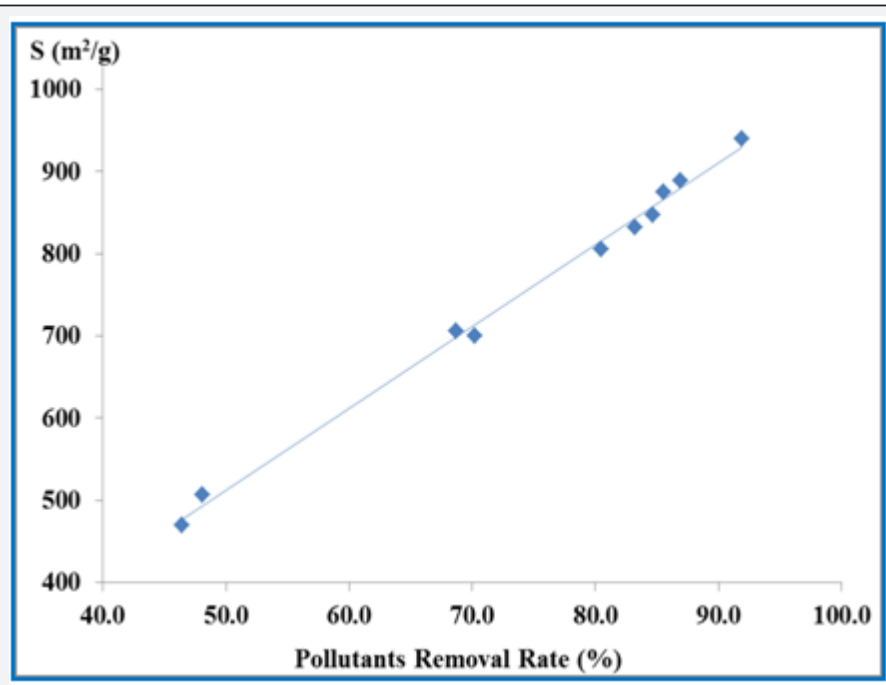

Figure 5: Relation between pollutants removal rate and activated carbons specific area, during pollutants removal from automotive engines combustion gases.

Table 7: Average values of pollutants removal during automotive engines combustion.

\begin{tabular}{|c|c|c|c|c|c|}
\hline Gas & Calibration sample & $\begin{array}{c}\text { Limit Value 24 h } \\
\text { (ppm)* }\end{array}$ & $\begin{array}{c}\text { Gas Conc. Before A.C. } \\
\text { (ppm) }\end{array}$ & $\begin{array}{c}\text { Gas Conc. After A.C. } \\
\text { (ppm) }\end{array}$ & Dismissing Rate (\%) \\
\hline $\mathrm{CO}$ & 500 & 500 & 366 & 41 & 88.8 \\
\hline $\mathrm{SO}_{2}$ & 400 & 50 & 367 & 52 & 85.8 \\
\hline $\mathrm{NO}_{2}$ & 150 & 40 & 91 & 26 & 71.4 \\
\hline $\mathrm{H}_{2} \mathrm{~S}$ & 150 & 150 & 148 & 37 & 75.0 \\
\hline
\end{tabular}

A proper choice of the parameters of chemical and physical activation such as temperature, activation time, activates agent, etc., permits getting universal adsorbents showing very good adsorption properties towards such pollutants as $\mathrm{SO}_{2}, \mathrm{CO}, \mathrm{NO}_{2}$ and $\mathrm{H}_{2} \mathrm{~S}$, however more studies are needed.

\section{Conclusion}

Agricultural wastes studied here are a feasible alternative for the synthesis of activated carbons for pollutants removal during automotive engines operation. The main features that make these products feasible for the diminishing of automotive engines emission are their high adsorption capacity, approaching its efficiency to the commercial Catalytic Converters such as the cheaper costs and its renewability. Based on these results the granular activated carbons studied, produced in large amounts, are fully exploitable for combustion gases treatment. The complex composition of the flue gas with $\mathrm{SO}_{2}, \mathrm{CO}, \mathrm{NO}_{2}$ and $\mathrm{H}_{2} \mathrm{~S}$ can be successfully analyzed with good compound separation and repeatability. The method used in this investigation would be also be suitable for combustion toxicology researches and could possibly be easily modified to analyze these gases when they are liberated from biological sources [27].

\section{Acknowledgment}

The author wishes to acknowledge Maria Andrea Camerucci and Ana Lia Cavalieri from Mar del Plata University, Argentina, they provided a crucial help in the experiments of this work.

\section{References}

1. Bland AE, Newcomer J, Zhang TM, Sellakumar KM, Hack H, et al. (2010) A Novel Integrated Oxy-Combustion and Flue Gas Purification Technology: A near Zero Emissions Pathway. Proceeding of International Advanced Coal Technologies Conference, Laramie, Wyoming, China, p. 23-24.

2. Mengmeng W, Zhiming D, Taiwen X (2014) Analysis and Purification of the Combustion Gas of Gas Generant. Procedia Engineering Journal 84: 826-833.

3. Ferguson CR, Kirkpatrick AT (2001) Internal Combustion Engines. Second Edition, John Wiley \& Sons, New York, USA.

4. Li YP, Wang B, Fang YL, Lin AB (2008) Activated coke combined desulfuration and de-nitration technology and its application prospects. Journal of Chemical Industry \& Engineering 12: 6.

5. Sciubidło A, Nowak W (2012) Novel sorbents for flue gas purification. Journal of Power Technologies 92: 115-126.

6. Vunain E, Kenneth D, Biswick T (2017) Synthesis and characterization of low-cost activated carbon prepared from Malawian baobab fruit 
shells by $\mathrm{H}_{3} \mathrm{PO}_{4}$ activation for removal of $\mathrm{Cu}(\mathrm{II})$ ions: equilibrium and kinetics studies. Applied Water Science 7: 4301-4319.

7. Mazziotti di Celso G, Karatza D, Lancia A, Musmarra D, Prisciandaro M (2013) Limestone-gypsum flue gas desulfurization process: modeling of catalyzed bisulfite oxidation. Journal of Chemical Engineering Transactions 32: 781-786.

8. Ritter R, Stoffregen T, Schödel N, Winkler F (2013) NOx processing experiences for removal in the $\mathrm{CO}_{2}$ plant in the Oxyfuel combustion process. Proceeding of 3rd Oxy-fuel Combustion Conference, Ponferrada, Spain, p. 9-13.

9. Elliott MA, Nebel GJ, Rounds FG (2012) The Composition of Exhaust Gases from Diesel, Gasoline and Propane Powered Motor Coaches. Journal of the Air Pollution Control Association 5: 103-108.

10. Bandosz TJ (2006) Activated Carbon Surfaces in Environmental Remediation. Academic Press, New York, USA.

11. Elkady MF, Hussein MM, Salama MM (2015) Synthesis and Characterization of Nano-Activated Carbon from El Maghara Coal, Sinai, Egypt to be Utilized for Wastewater Purification. American Journal of Applied Chemistry 3: 1-7.

12. Jiang H, Chen H (2011) Research on preparation of activated carbon from agricultural wastes and analysis of pore structure. Energy Procedia 11: 3629-3633.

13. Shawabkeh RA, Al-Harthi M, Al-Ghamdi SM (2014) The Synthesis and Characterization of Microporous, High Surface Area Activated Carbon from Palm Seeds. Energy Sources 36: 93-103.

14. Sumathi S, Bhatia S, Lee KT, Mohamed AR (2009) Optimization of microporous palm shell activated carbon production for flue gas desulphurization: Experimental and statistical studies. Journal of Bioresource Technology 100: 1614-1621.

15. Davini P (2002) Flue gas treatment by activated carbon obtained from oil-fired fly ash. Carbon 40: 1973-1979.

16. Shah M, Degenstein N, Zanfir M, Kumar R, Bugayong J, et al. (2011) Purification of oxy-combustion flue gas for SOx/NOx removal and high $\mathrm{CO}_{2}$ recovery. Proceeding of $2^{\text {nd }} \mathrm{Oxy}$-fuel Combustion Conference, New York, USA
17. Wang X, Ma X, Zhao S, Wang B, Song C (2009) Nano-porous molecular basket sorbent for $\mathrm{NO}_{2}$ and $\mathrm{SO}_{2}$ capture based on a polyethylene glycolloaded mesoporous molecular sieve. Journal of Energy Environmental Sciences 2: 878-882.

18. Villegas PJ, Camerucci MA, Quintana-Puchol R (2014) Kinetic of the Thermal Conversion Processes of Tropical Biomasses. Handbook on Emerging Trends in Scientific Research 1: 37-43.

19. Kazmierczak J, Nowicki P, Pietrzak R (2013) Sorption properties of activated carbons obtained from corncobs by chemical and physical activation. Adsorption 19: 273-281.

20. Shah M, Degenstein N, Zanfir M, Kumar R, Bugayong J, et al. (2011) Purification of oxy-combustion flue gas for SOx/NOx removal and high $\mathrm{CO}_{2}$ recovery. Proceeding of 2nd Oxy-fuel Combustion Conference, New York, USA.

21. Villegas PJ, Casañola GM, Dieguez Santana K (2016) Prediction of the adsorption capacity of activated carbons using physicochemical parameters, mechanical properties and elemental composition. International Journal of Chem-Tech Research 9: 740-748.

22. Andoni A, Xhaxhiu K, Taraj K, Çomo A (2014) An Adsorption Method for Characterization of Surface Area and Pore Size of Solid Surfaces. Asian Journal of Chemistry 26: 6833-6838.

23. Brunauer S, Emmett PH, Teller E (1938) Adsorption Gases in Multimolecular Layers. Journal of American Chemical Society 60: 309-319.

24. Sujová E (2008) The knowledge of wood gas purification by adsorption cartridge filters follow up with its application in combustion engines. Geo Science Engineering Journal 54: 33-41.

25. Dhole V, Kadam V (2018) Analysis of Flue Gases with GC and TCD Detection.

26. Endecott BR, Sanders DC, Chaturvedi AK (1996) Simultaneous Gas Chromatographic Determination of Four Toxic Gases Generally Present in Combustion Atmospheres. Journal of Analytical Toxicology 20: 189194.

27. Carrott PJ, Mourao PA, Ribeiro Carrott ML (2006) Controlling the micropore size of activated carbons for the treatment of fuels and combustion gases. Journal of Applied Surface Science 252: 5953-5956.

\begin{tabular}{l} 
Your next submission with Juniper Publishers \\
will reach you the below assets \\
- Quality Editorial service \\
- Swift Peer Review \\
- Reprints availability \\
- E-prints Service \\
- Manuscript Podcast for convenient understanding \\
- Global attainment for your research \\
- Manuscript accessibility in different formats \\
( Pdf, E-pub, Full Text, Audio) \\
- Unceasing customer service \\
Track the below URL for one-step submission \\
https://juniperpublishers.com/online-submission.php \\
\hline
\end{tabular}

